\title{
FUNCTIONAL OUTCOME OF SURGICAL MANAGEMENT OF CLOSED TIBIAL CONDYLAR FRACTURES IN ADULTS
}

Ravish V. N1 , Arvind Kumar² I. Suresh ${ }^{3}$, Rakesh Mohan R ${ }^{4}$

\section{HOW TO CITE THIS ARTICLE:}

Ravish V. N, Arvind Kumar, I. Suresh, Rakesh Mohan R. "Functional outcome of Surgical management of closed Tibial Condylar Fractures in Adults". Journal of Evolution of Medical and Dental Sciences 2014; Vol. 3, Issue 09, March 3; Page: 2327-2339, DOI: 10.14260/jemds/2014/2143

ABSTRACT: BACKGROUND AND OBJECTIVE: Tibial plateau fractures are one of the commonest intra-articular fractures. It results from indirect coronal or direct axial compressive forces. It comprises of $1 \%$ of all fractures. These fractures encompass many and varied fracture configurations that involve medial, lateral or both plateaus with many degrees of articular depressions and displacements. Being one of the major weight bearing joints of the body, fractures around it will be of paramount importance. METHODS: 30 cases of tibial plateau fractures treated by various modalities were studied from September 2009 to september 2011 at Kempegoda Institute of Medical Sciences and followed for minimum of 6 months. RESULTS: The selected patients evaluated thoroughly clinically and radiologically, after the relevant lab investigations, were taken for surgery. The indicated fractures treated as per the SCHATZKER'S types, accordingly with CRIF with percutaneous cannulated cancellous screws, MIPPO with LCP/ Butress plate and screw, ORIF with buttress plate/ LCP and screw. Early range of motion started soon after the surgery. No weight bearing upto 6 weeks. The full weight bearing deferred until 12 weeks or complete fracture union. Immobilization in insecurely fixed fractures continued for 3-6 weeks by POP cast. The knee range of motion was excellent to very good, gait and weight bearing after complete union was satisfactory. Infection in two cases and stiffness in 2 cases were seen and there was no non-union in our cases. CONCLUSION: Surgical management of tibial condylar fractures will give excellent anatomical reduction and rigid fixation to restore articular congruity, facilitate early motion, hence to achieve optimal knee function and reducing post-traumatic osteo arthritis.

KEYWORDS: Fracture, tibial condyle, buttress plate, locking compression plate, MIPPO.

INTRODUCTION: Tibial plateau fractures are one of the commonest intra-articular fractures. It results from indirect coronal or direct axial compressive forces. It comprises of $1 \%$ of all fractures. These fractures encompass many and varied fracture configurations that involve medial, lateral or both plateaus with many degrees of articular depressions and displacements. Each fracture type has its own characteristic morphology and response to the treatment. It is essential to determine the force of injury since high-energy trauma is associated with considerable soft tissue and neurovascular damage. Apart from tibial plateau bony injury, meniscal tear and ligament injuries should also be assessed. ${ }^{1}$

The stationary lower limb may be struck by a moving object; this is the common pedestrian injury, the so called "BUMPER FRACTURE", since the bumper of most vehicles being placed roughly at knee height. The exposed knee joint may be subjected to angulation, rotation or shearing strains and when the subject is upright, his body weight assists in the injury and he falls over.

Fractures of the upper tibia are difficult to treat, apart from the usual problems of confining patients to bed. Conservative treatment at any age, may be complicated by knee stiffness, malunion 
and nonunion. Open reduction and internal fixation has been advocated using various implants including Buttress plates, locking compression plates, cancellous screws, etc., to achieve good fracture union and optimal knee function.

This study was undertaken with the intention to Study the surgical anatomy and reduction techniques in closed tibial condylar fractures in adults of schatzker"s type 1 to 6 and also to evaluate the various options available for internal fixation of these injuries. Finally the functional outcome of patients treated with open reduction and internal fixation by plating was assessed with appropriate scoring system.

METHODOLOGY: The cases studied for this series were included from inpatients of KEMPEGOWDA INSTITUTE OF MEDICAL SCIENCES HOSPITAL, BANGALORE. The total number of cases studied was 30. The average age of patient was 38.7 years with the oldest patient 70 years and youngest 20 years. The aim of treatment that is, SURGICAL MANAGEMENT OF CLOSED TIBIAL CONDYLAR FRACTURES was to obtain a stable, pain free, mobile joint, and to correlate the radiological findings with the type of fracture and the functional end result.

\section{PERIOD OF STUDY: TWO YEARS:} INCLUSION CRITERIA:
a) Age/sex, Above 18 years, both sex
b) Closed Fractures
c) Duration - within one week
d) Schatzker"s type 1,2,3,4,5, and 6 fracture
e) Associated ligamentous injuries
f) Associated fibular upper end fracture

\section{EXCLUSION CRITERIA:}
a) Age below 18 years
b) Compound fractures
c) Other limb fractures and diseases
d) Pathological Fractures
e) Associated neurovascular injury
f) Patients who are medically not fit for surgery

Patients who were selected for the study were evaluated with Anteroposterior and lateral radiographs of the knee joint, C T SCAN of the knee joint (not mandatory for all) and M R I of the knee joint (if needed to rule out ligamentous injury)

The Ethical clearance for this study has been obtained from institution. As soon as the SURGERY was planned, the following procedures were regularly followed

1. Routine preoperative investigations, treatment of the co-morbidities of the patient was done with appropriate references to the concerned specialties. Fitness for the surgery was taken from the physicians. Use of antibiotics pre-operatively and continued till the removal of sutures. Joint stability was assessed under anesthesia. All cases were operated under c-arm guidance. 


\section{ORIGINAL ARTICLE}

\section{CANCELLOUS BONE SCREWS:}

1. $5.0 \mathrm{~mm}$ cancellous bone screw with $8 \mathrm{~mm}$ spherical head and $3.5 \mathrm{~mm}$ hexagonal recess, thread length $16 \mathrm{~mm}$ and $32 \mathrm{~mm}$ in the partially threaded screws, with $4.5 \mathrm{~mm}$ shaft, $3 \mathrm{~mm}$ core, 3.2 $\mathrm{mm}$ drill bit and $6.5 \mathrm{~mm}$ tap.

2. $4.5 \mathrm{~mm}$ cortical bone screw, with $4.5 \mathrm{~mm}$ shaft, $3 \mathrm{~mm}$ core, $3.2 \mathrm{~mm}$ drill bit and $4.5 \mathrm{~mm}$ tap.

3. $4 \mathrm{~mm}$ cancellous bone screw, with $6 \mathrm{~mm}$ head, $2.5 \mathrm{~mm}$ hexagonal recess, core diameter $1.9 \mathrm{~mm}$, $1.7 \mathrm{~mm}$ pitch, $2.5 \mathrm{~mm}$ drill bit and $4 \mathrm{~mm}$ tap.

4. K-wires.

\section{CANULLATED CANCELLOUS SCREW FIXATION:}

PROCEDURE: Under anesthesia patient put in supine position on table, Parts scrubbed, painted, and draped.

Under the guidance of image intensifier, fracture reduced and guide wire inserted percutaneously and drilling was done with cannullated drill bit.

Then appropriate sized $6.5 \mathrm{~mm}$ cannullated cancellous screws were inserted. Reduction confirmed under image intensifier.
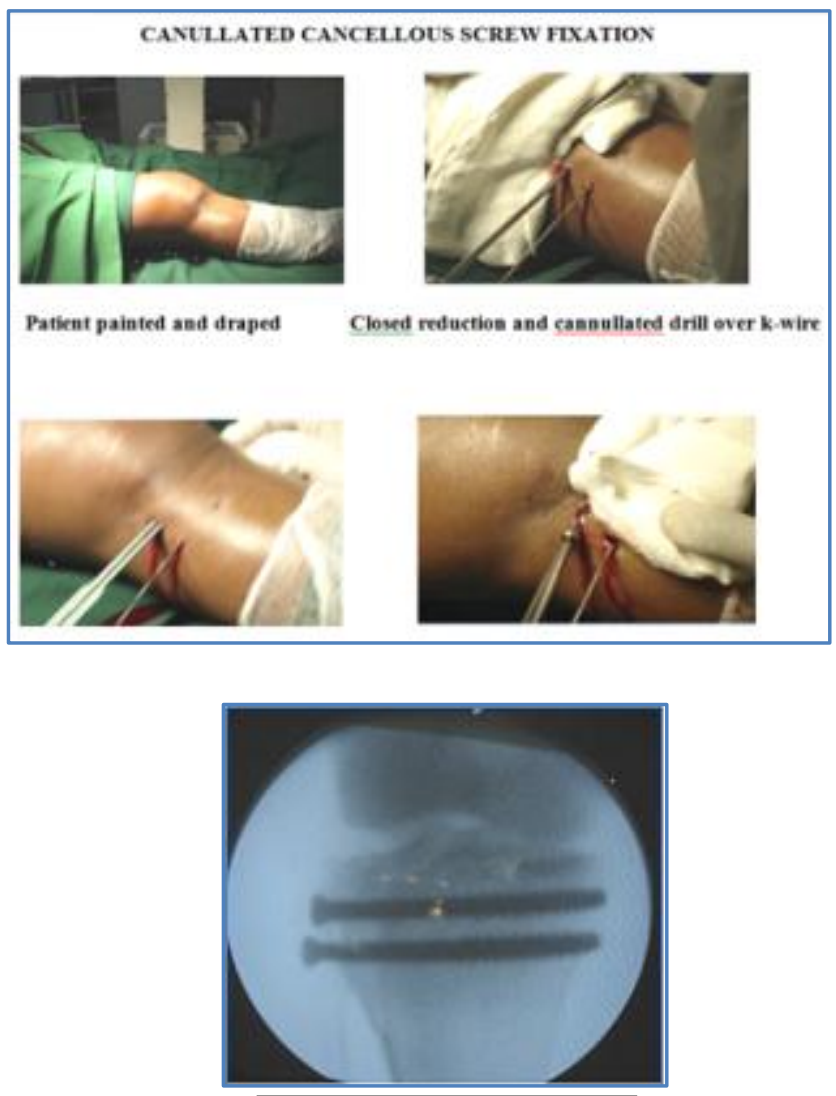

Image Intensifier 


\section{ORIGINAL ARTICLE}

\section{BUTTRESS PLATES:}

T plate

L buttress plate with right and left offset.

\section{MIPPO WITH BUTTRESS PLATE AND SCREWS:}

PROCEDURE: Under anesthesia patient put in supine position on table, parts scrubbed, painted, and draped. Then a minimal incision was made over the antero lateral aspect of Left knee. Fracture reduction done under the guidance of image intensifier.

Buttress plate was inserted over the periosteum and fixed with two k-wires. Using cannullated drill bit, drilling was done and length measured with indirect depth gauze.

Then appropriate size $6.5 \mathrm{~mm}$ cannullated cancellous screws were inserted and distally 4.5 mm cortical screws were inserted after drilling. Reduction confirmed under image intensifier.

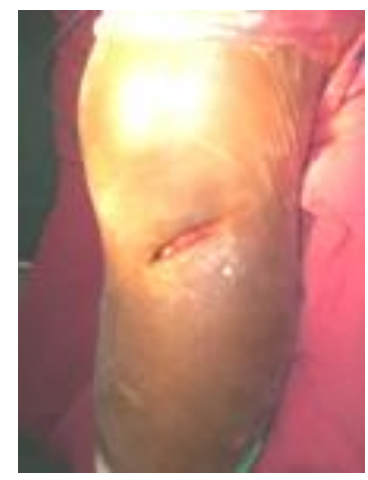

Skin Incision

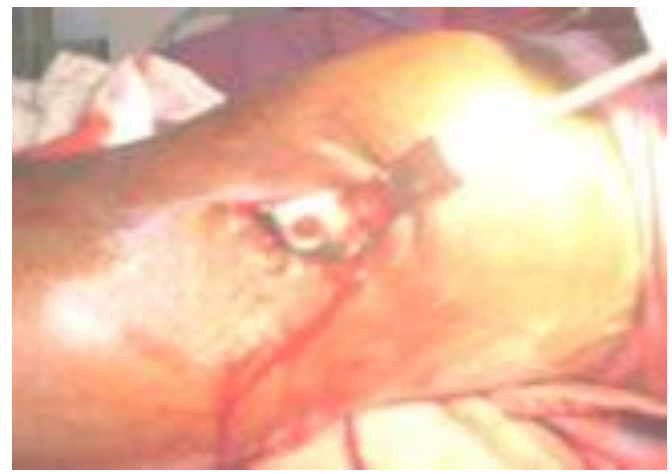

Insertion of the Plate

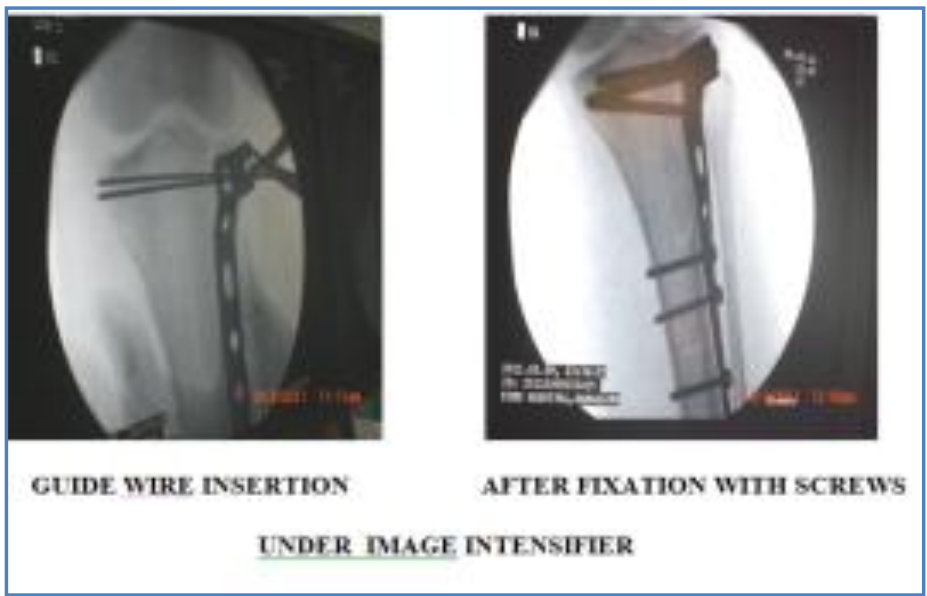




\section{ORIGINAL ARTICLE}

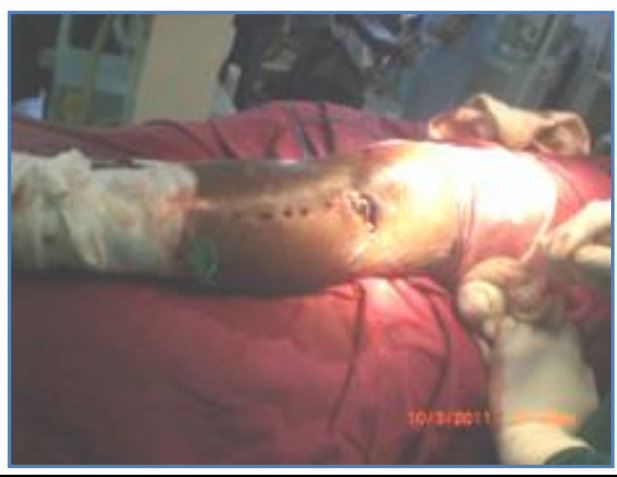

AFTER FIXATION OF THE PLATE WITH SCREWS

\section{ORIF WITH PLATE AND SCREWS:}

PROCEDURE: Under anesthesia patient put in supine position on table parts scrubbed, painted and draped. Using antero lateral approach skin incision was made and fracture site exposed. Then fracture was reduced directly and contoured plate was inserted and using cannullated drill bit, drilling was done.

Then length was measured and appropriate sized $6.5 \mathrm{~mm}$ Cannullated cancellous screws were inserted and fixed. Distally 3.2 drill bit was used for drilling and $4.5 \mathrm{~mm}$ cortical screws were inserted and fixed. Reduction confirmed under image intensifier.
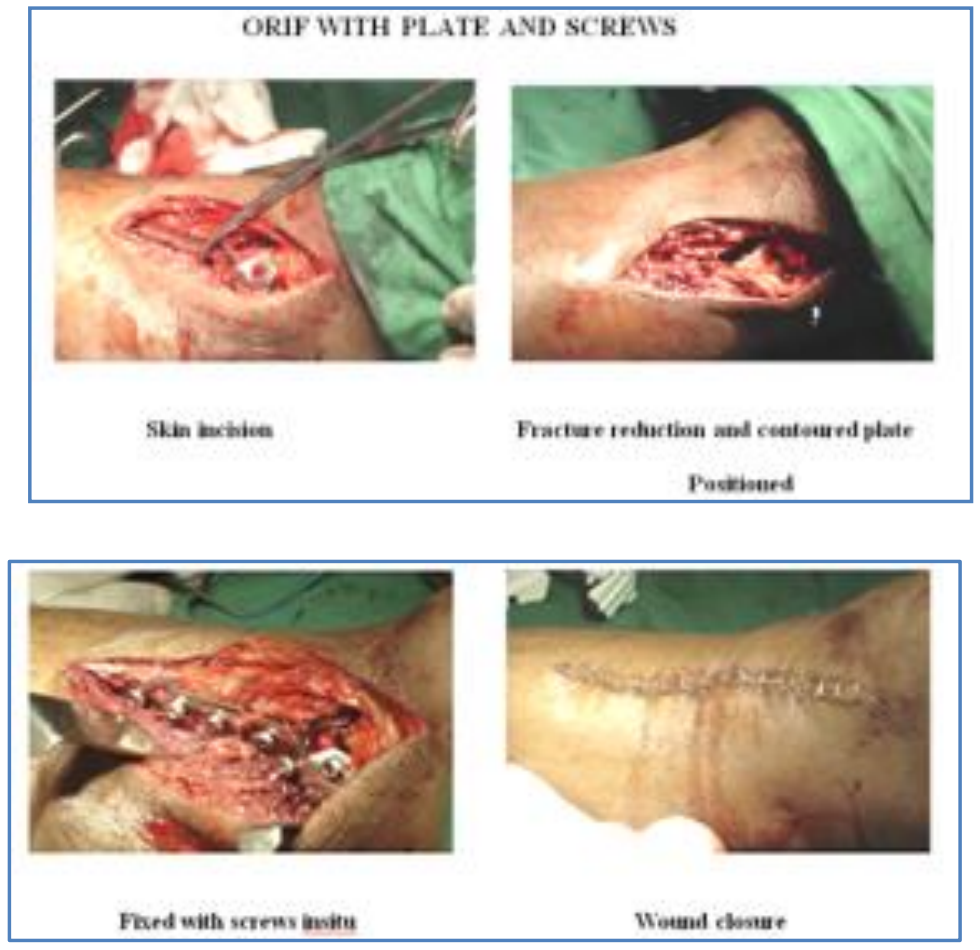

Post-operatively mobilized without weight bearing on $2^{\text {nd }}$ to $4^{\text {th }}$ day, patients are advised active quadriceps exercises, Hip and knee flexion-extension exercises. Partial weight bearing started at 6 weeks. Full weight bearing was possible by 8-12 weeks depending on the fracture configuration, callus response. 


\section{ORIGINAL ARTICLE}

Assessment was done at regular intervals of 6 weeks, 12 weeks and 6 months. At each followup visit, patient is evaluated clinically, radiologically and complications are noted.

\section{RADIOGRAPHS:}
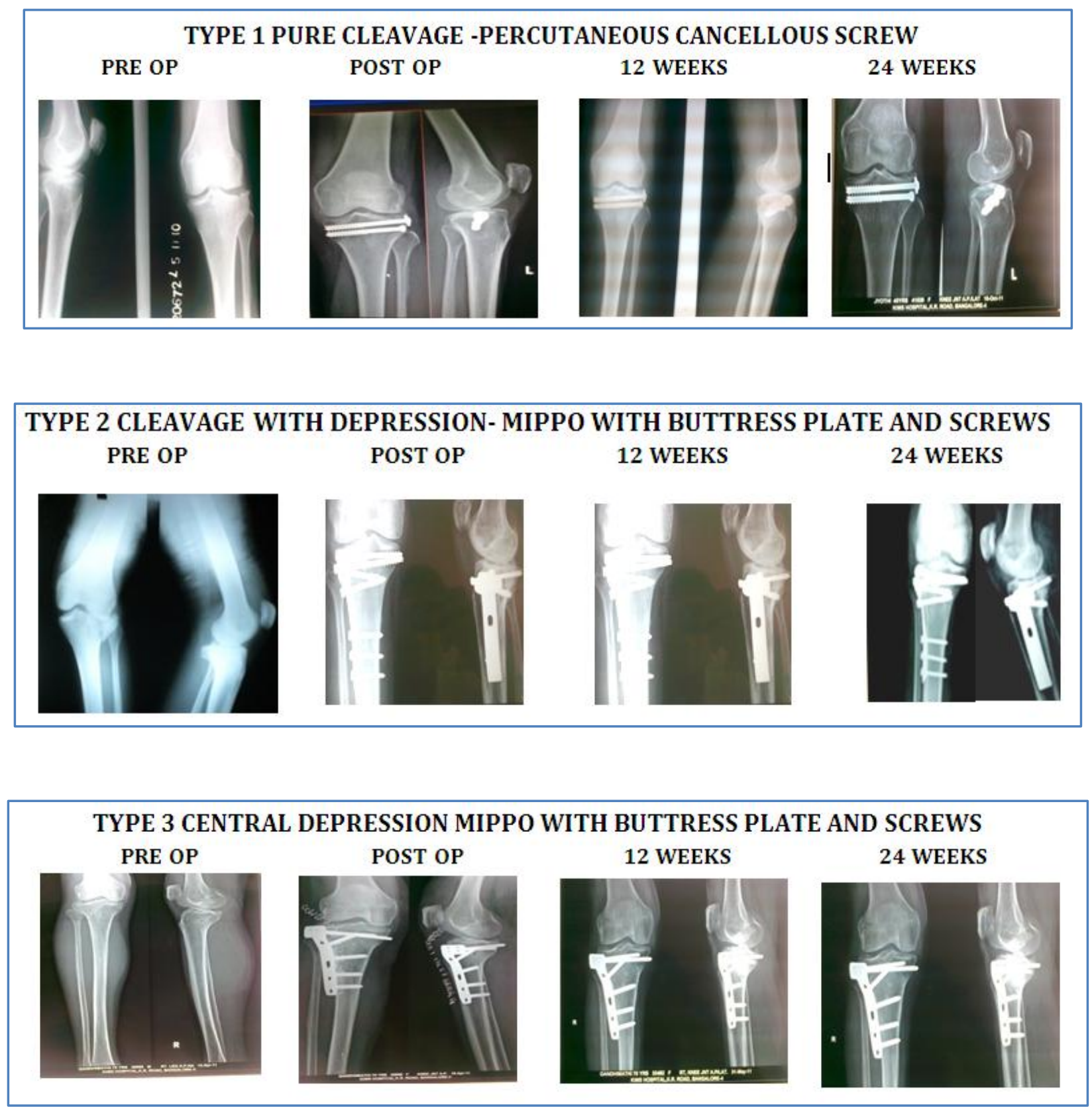


\section{ORIGINAL ARTICLE}
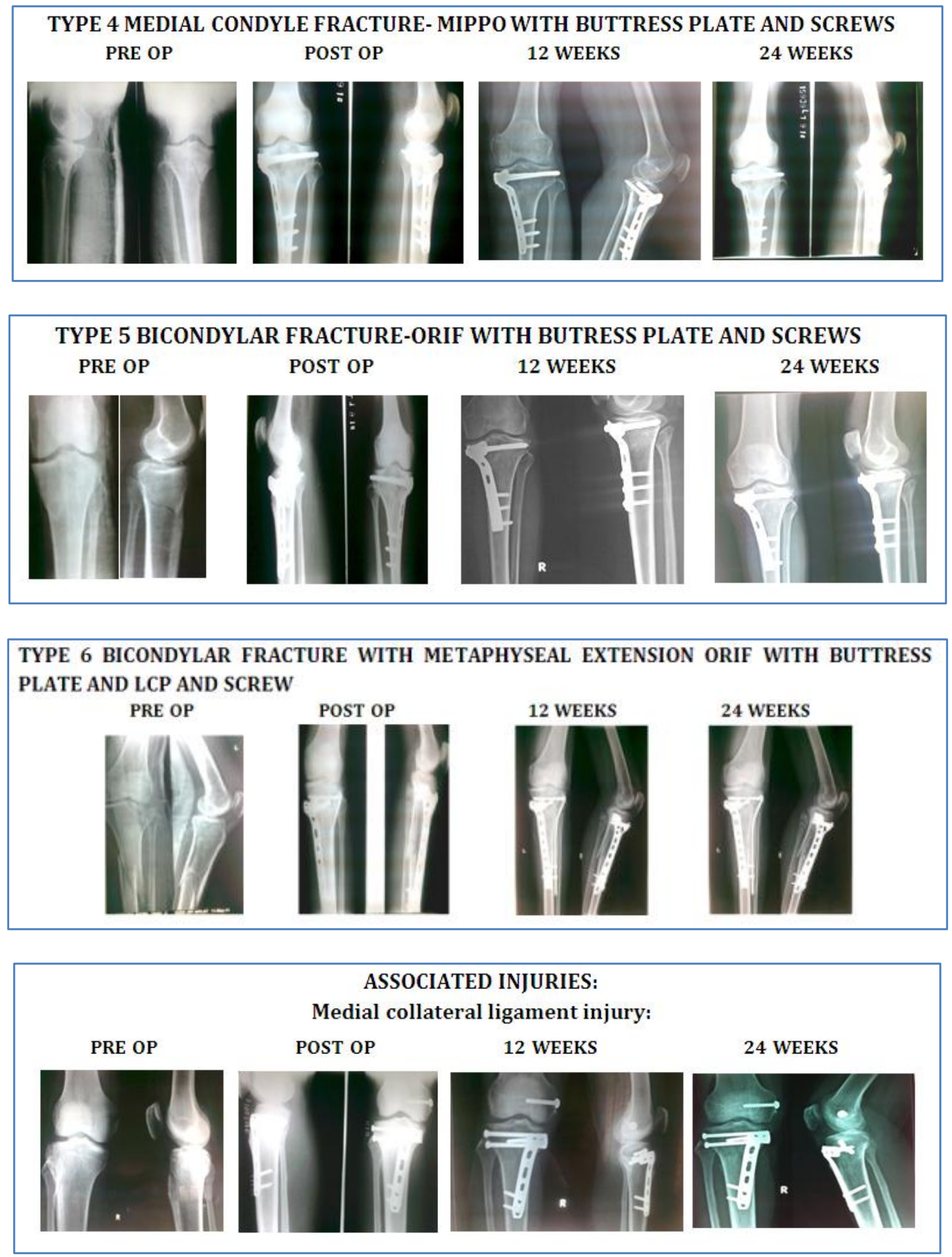

J of Evolution of Med and Dent Sci/ eISSN- 2278-4802, pISSN- 2278-4748/ Vol. 3/ Issue 09/Mar 3, 2014 


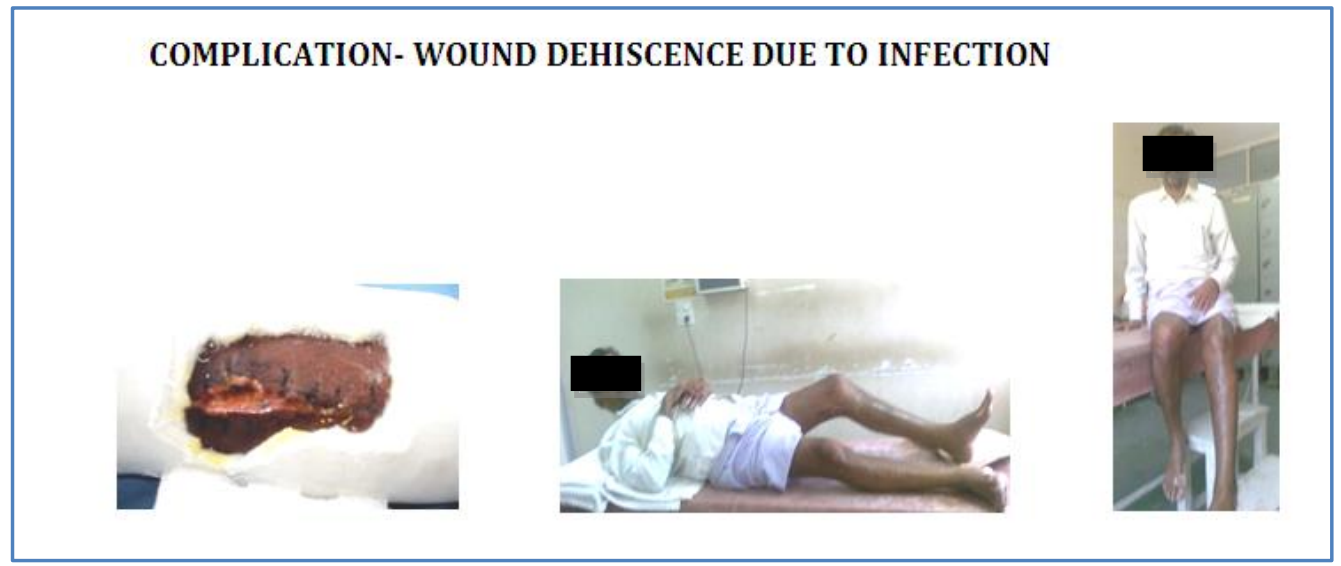

\section{CLINICAL RESULT}

\section{RESULTS:}

AGE INCIDENCE: In our series, the majority of the patients are found to be between the age group of 20-30 years (12) and 41-50 years (10).

The least number of cases are found in the age group between 61-70 years .The mean age of the patients was 38.7 years.

SEX INCIDENCE: This incidence of sex versus upper tibial fractures can be attributed to an overwhelming large proportion of male patients, because in our Indian setup, the female population largely working indoors or in the agricultural fields and do not indulge themselves in travelling or outdoor activities.

OCCUPATION: Upper tibial fracture is seen in people with a high level of activity, (laborer) who indulge themselves in travelling, because majority of the injuries is due to R.T.A.

The groups like employee, businessman have a comparatively lesser fracture rate as they do not indulge in high level of activity, but if these group were to sustain a fracture, it is mainly due to automobile accidents. Housewives tend to have violent injuries commonly due to automobile accidents, fall from height, when they climb up ladder or stool to pick up objects from the shelves.

MODE OF VIOLENCE: In this series, the majority of the patients treated are due to road traffic accidents or automobile accidents, to the extent of $70 \%$.

LATERALITY OF FRACTURES: In our series, there is right sided predominance, compared to the left side.

\section{TYPE OF FRACTURE:}

SCHATZKER'S CLASSIFICATION: In our series, the majority of the fractures were found to be of type II and type $\mathrm{V}$ fracture types i.e. Cleavage with depression fractures (30\%) and bicondylar fractures (26.67\%) respectively. 


\section{ORIGINAL ARTICLE}

METHODS OF TREATMENT: The ultimate objective of the surgery was to achieve accurate articular alignment, axial alignment and rigid fixation of the fracture fragments. $30 \%$ of the cases were treated with Buttress plate and screws with MIPPO technique. Closed reduction and cannulated screw fixation was done in $26.67 \%$

\section{ASSOCIATED INJURY:}

1) Medial collateral ligament (2) The ligament was surgically repaired during fracture treatment.

2) Anterior cruciate ligament (2) patient refused ACL Reconstruction surgery yet he did not show functional disability but only the clinical instability.

We did not come across any other ligament injuries around the knee joint.

PERIOD OF IMMOBILISATION IN WEEKS: None of the patients were immobilized when secure, rigid fixation was done.

When there was doubt about rigidity of fixation, associated ligament injury or osteoporosis, the immobilization extended preferably in above knee cast upto 3 weeks. Two cases of infection and one case of severe metaphyseal comminution had to immobilize 3-6 weeks

Most of the cases had good range of painless knee motion $\left(0-130^{\circ}\right)$, except for the two patients who developed knee stiffness.

COMPLICATIONS: All fractures united within expected time. There was not a single case of nonunion noted in our series. Average time for union was 14 weeks (range 10-22 weeks). There were two cases of wound infection which were associated with stiffness of the knee joint.

CLINICAL RESULTS: All cases were graded based on RASSMUSSEN"S CRITERIA FOR EVALUATION OF RESULTS 1 :

OUTCOME: Out of 30 cases treated with surgical procedure, 20 cases had excellent result, 6 cases had with good result, fair in 2 cases and 2 cases of poor result. In our study it was found that high velocity injuries (type IV - VI) have poorer outcome than low velocity injuries (type I-III). ${ }^{2}$

DISCUSSION: Tibial plateau fractures, one of the commonest intra articular fractures, are major traumatic injury occurring as a result of RTA, fall from height, violence etc. It is sometimes associated with other bony or soft tissue injuries. Any fracture around the joint (especially weight bearing knee joint in the lower limb) is of paramount importance as would result in significant morbidity and quality of life. Hence the treatment of upper tibial fractures with intra articular extension has become a challenge for the orthopedic surgeons.

Keeping our aims of the study at high, we presented the clinical study of surgical treatment of 30 closed tibial plateau fractures. The analysis of the results were made in terms of - age of the patient, sex distribution, occupation, mode of violence, laterality of the fracture, analysis of the types, modalities of treatment, complications associated injuries and the functional outcome.

We have endeavored to present the various types of tibial plateau fractures in our Indian setup. It is found that the zeal for modernization, mechanization and industrial development made more automobile accidents due to increase in the number of population and automobiles. 
The majority of fractures occur between the age of 20 and 50 years with maximum incidence being involving the productive age group 20-30 years (40\%). The mean average of the patient was 38.7 in our study.

Boune in 1981 also found that the majority of the patients are aged between 15-55 years with an average of 38.5 years, correlates well with the study. Seppo also showed age incidence 20-60 years with an average of 39.8 years which correlates with the present study. ${ }^{3}$

In our series majority of the patients were males $70 \%$. This can be attributed to our Indian setup where the female population largely work indoor or in agricultural fields and less prone for injuries. So the significant proportion of tibial plateau fractures related sex distribution was not available to comment on them.

Occupationally tibial plateau fractures were seen in people with high level of activity, movement and travel. It is most commonly seen with people who do high level of activity like laborers. In our series majority were laborers (36.7\%), followed by housewives (26.7\%), student (16.7\%), employee (10\%) and businessman (10\%).

In our study the commonest mode of injury being the road traffic accident (70\%), next common being fall (30\%).

There was significant preponderance to right side in the laterality of the fracture. The right tibia was affected in $66.7 \%$ and left tibia in $33.3 \%$ of cases.

In this series we studied 30 cases of simple tibial plateau fractures treated only by surgical methods. Different authors use different criteria for the surgical management of these fractures. SEPPO E. HONKONEN conducted 130 tibial plateau fractures. ${ }^{3}$

Taking into consideration of

- Condylar widening of $>5 \mathrm{~mm}$

- Lateral condyle step off $>3 \mathrm{~mm}$

- All medial condylar fractures for the surgical management.

In our study, the indications for the surgery were the same standard indications as for those tibial plateau fractures. $3 \mathrm{~mm}$ depression was considered as an indication for surgery in our series.

Name of the authors

\begin{tabular}{|l|c|c|}
\hline NAME OF THE AUTHOR & YEAR & AMOUNT OF DEPRESSION \\
\hline BURRI $^{4}$ & 1979 & $1 \mathrm{~mm}$ \\
\hline HOHL $^{5}$ & 1979 & $5 \mathrm{~mm}$ \\
\hline DAVID SEGAL $^{6}$ & 1991 & $5 \mathrm{~mm}$ \\
\hline SEPPO $^{3}$ & 1993 & $3 \mathrm{~mm}$ \\
\hline OUR STUDY $^{2}$ & 2011 & $3 \mathrm{~mm}$ \\
\hline
\end{tabular}

In our series, Schatzker's type II and type $\mathrm{V}$ dominated the total fractures making $56.7 \%$. It is also to be noted that bicondylar fracture was common. 


\begin{tabular}{|c|c|c|c|}
\hline $\begin{array}{c}\text { Type of } \\
\text { fracture }\end{array}$ & $\begin{array}{c}\text { Tampere hospital } \\
\text { Finland } \\
\text { \% of cases }\end{array}$ & $\begin{array}{c}\text { Wellesley hospital } \\
\text { Toronto } \\
\text { \% of cases }\end{array}$ & $\begin{array}{c}\text { 0UR STUDY } \\
\text { \% of cases }\end{array}$ \\
\hline TYPE 1 & 11.5 & 6 & 16.7 \\
\hline TYPE 2 & 30.5 & 25 & 30 \\
\hline TYPE 3 & 9.9 & 36 & 3.3 \\
\hline TYPE 4 & 9.2 & 10 & 16.9 \\
\hline TYPE 5 & 21.3 & 3 & 26.7 \\
\hline TYPE 6 & 17.5 & 20 & 6.7 \\
\hline
\end{tabular}

The method of fixation for particular type of fracture was formulated depending on the morphology of the fracture and quality of the bone. . So each case was individualized and treated accordingly to achieve the articular alignment, axial alignment and rigid fixation of the fracture. Most of the type I, some type II were treated with percutaneous cancellous screw fixation. The split fracture, of $>3 \mathrm{~mm}$ displacement was treated by MIPPO with buttress/ locking compression plate and screws.

In 27 cases the articular depression was corrected by traction on fracture table reduction and cortical window with joy stick manipulation, correction maintained with guide wires until definitive fixation.

In 3 cases even after reduction by traction on fracture table $>3 \mathrm{~mm}$ articular depression persisted (Include 1 case Type III, 1 case Type V and 1 case Type VI). These cases were managed additionally with articular surface elevation using iliac crest bone grafting.

All the medial plateau fractures were treated surgically as illustrated by Seppo E. in 1993. The patients with collateral ligament injuries were managed intraoperatively by suturing when required or POP cast immobilization for 3-4 weeks.8,9,10 The period of immobilization was again individualized depending on the security of rigid fixation and associated ligamentous injuries. The benefits of early knee motion include - reduce knee stiffness and improved cartilage healing (regeneration). However, these benefit are to be cautiously balanced by risks involved with early mobilization, including loss of fracture reduction, failure of internal fixation and compromised ligament and soft tissue healing. Schatzker, Robert McBroom in 1978, Magonhobi, Steven and Gauscwitz in 1984 stated that the prognosis is given by the degree of displacement, type of fracture, method of treatment and quality of postoperative care. ${ }^{7}$

Patients who had $<3 \mathrm{~mm}$ articular step off were treated conservatively which were not included in our study.

The problem faced by us during the study in two of the cases were infection and wound dehiscence, hence immobilization was more in these patients. The infection might be attributed to nosocomial infection. Inspite with all the ligament injuries and complications, we are able to achieve $66.7 \%$ excellent result 20\%, good results (overall $86.7 \%$ acceptable results) with our surgical care using various standard fixation methods. In addition we have $6.7 \%$ fair and $6.7 \%$ poor results in terms of functional outcome. These results are comparable and on par with other documented standard studies. 


\begin{tabular}{|c|c|}
\hline STUDY & RESULTS \\
\hline Rambold 1992 & $-93 \%$ acceptable \\
\hline Seppo E. 1993 & - 86\% satisfactory \\
\hline Schatzker 1986 & - 86\% satisfactory \\
\hline Our study 2011 & - 86.7\% satisfactory \\
\hline
\end{tabular}

Recent trend is to do minimal invasive surgeries possible. Many centers have shown good results with arthroscopic assisted internal fixation, hybrid external fixator, minimal internal fixation supplemented with external fixation, Illizarov ring fixation and most recently the MIPPO (Minimal Invasive Percutaneous Plate Osteosynthesis). ${ }^{11,12,13,14}$ We have employed the MIPPO technique and had satisfactory results with the method proving that minimal invasive surgery leads to less operative trauma to the soft tissues thereby reduction in the period of immobilization and less chances of infection, stiffness leading to excellent functional outcome of the knee joint . Hence, to conclude, the surgical management of tibial plateau fractures is challenging, gives excellent anatomical reduction, rigid fixation to restore articular congruity, facilitate early knee motion, thus achieving optimal knee function and thereby preventing post-traumatic osteoarthritis.

CONCLUSION: Tibial condylar fractures are increasing in their incidence (especially the high velocity injuries) with the increase in the number of road traffic accidents. These fractures need optimum treatment as they involve the productive age groups.

Anatomic reduction, accurate axial and articular alignment with rigid fixation should be the objective of the treatment to achieve a stable and functional knee joint. Preoperative soft tissue status and associated ligamentous injuries and their repair at right time, significantly changes the functional outcome.

Hence, to conclude, the surgical management of tibial plateau fractures is challenging, gives excellent anatomical reduction, rigid fixation to restore articular congruity, facilitate early knee motion, thus achieving optimal knee function and thereby preventing post-traumatic osteoarthritis.

\section{BIBLIOGRAPHY:}

1. Rassmussen P.S.: Tibial condylar fractures. Impairment of knee joint stability as an indication for surgical treatment. J Bone and Joint Surg., 55-Am 1331-1350, Oct 1973.

2. Mikulak SA and Gold SM. Small wire external fixation of high energy tibial plateau fractures. Clin Orthop 1998; 356:230-238.

3. Honkonen SE. Indications for surgical treatment of tibial condyle fractures. Clin Orthop 1994; 302: 199-205.

4. Burri G, Bartzke J, Coldewey J and E Mugglar. Fractures of the tibial plateau. Clin Orthop 1979; 138: 64.

5. Bowes DN and Hohl M. Tibial condylar fractures - evaluation of treatment and outcome. Clin Orthop 1982; 171: 105-108.

6. Segal D, Arati R, Malik, Merrick J, Wetzlar and Albert V. Early weight bearing of lateral tibial plateau fractures. Clin Orthop 1993; 294: 232-37.

7. Schatzkar J, Mc Broom R and Bruce D. The tibial plateau fractures - Toronto experience. Clin Orthop, 1979; 138: 94. 


\section{ORIGINAL ARTICLE}

8. Whittle AP and Wood II GW. Fractures of lower extremity chapter 51 in Compbells operative Orthopaedics Canale ST Ed; 10th edn, vol 3: New York, Mosby 2003; 2782-2796.

9. Dalamarter R, Hohl M and Hopp E Jr .Ligament injuries associated with tibial plateau fractures. Clin Orthop 1990; 250: 226.

10. Bennett WF and Browner B. Tibial plateau fractures- a study of associated soft tissue injury. J.Ortho.Trauma 1992; 6: 78.

11. Watson JJ and Wiss AD. Fractures of the proximal tibia and fibula, chapter 44 in Rockwood and Green's fractures in adults, Bucholz RW and Heckman JD Ed. 5th ed. Vol 2: Philadelphia, Lippincott Williams and Wilkins 2001; 1799-1839.

12. Marsh JL, Smith ST and Do TT. External fixation and limited internal fixation for complex tibial plateau fractures. J Bone \& Joint Surg May 1995; 77(Am): 661-673.

13. Buchko GM and Johnson DH. Arthroscopy assisted operative management of tibial plateau fractures. Clin Orthop 1996; 332: 29.

14. Jong-keun O, Chang-wug O, In-Ho J, Sung-Jung K, Hee-Soo K, Il-Hyung P et al. Percutaneous plate stabilisation of proximal tibial fractures. J Truama Aug 2005; 5 431-437.

\section{AUTHORS:}

1. Ravish V. N.

2. Arvind Kumar

3. I. Suresh

4. Rakesh Mohan R.

\section{PARTICULARS OF CONTRIBUTORS:}

1. Associate Professor, Department of Orthopaedics, KIMS, Bangalore.

2. Assistant Professor, Department of Orthopaedics, KIMS, Tamilnadu.

3. Professor Department of Orthopaedics and Medical Superintendant, KIMS, Bangalore.

4. Post Graduate, Department of Orthopaedics, KIMS, Bangalore. 